\title{
Screening and Identifying m6A Regulators in Pancreatic Cancer Based on The Cancer Genome Atlas Database
}

\author{
Bi Lin \\ Wenzhou Medical University First Affiliated Hospital: The First Affiliated Hospital of Wenzhou Medical University \\ Hongwei Sun \\ First affiliated hospital of Wenzhou Medical University \\ Dinglai Yu \\ First affiliated hospital of Wenzhou Medical University \\ Yukai Xiang \\ first affiliated hospital of wenzhou medical university \\ Jie Zhang \\ first affiliated hospital of wenzhou medical university \\ Shengchuan Chen \\ first affiliated hospital of wenzhou medical university \\ Shengjie Dai \\ first affiliated hospital of wenzhou medical university \\ Chaohao Huang ( $\nabla$ kirbylin2010@sina.com ) \\ Wenzhou Medical University First Affiliated Hospital: The First Affiliated Hospital of Wenzhou Medical University
}

\section{Research}

Keywords: pancreatic cancer, N6-methyladenosine, ALKBH5, m6A regulators, TCGA

Posted Date: October 28th, 2020

DOI: https://doi.org/10.21203/rs.3.rs-96939/v1

License: @ (1) This work is licensed under a Creative Commons Attribution 4.0 International License. Read Full License 


\section{Abstract}

Background: Pancreatic cancer is one of the most malignant tumors of the digestive system and its treatment has rarely progressed for the last two decades. Studies on m6A regulators for the past few years have seemingly provided a novel approach for malignant tumor therapy. m6A-related factors may be potential biomarkers and therapeutic targets. This research is focused on the gene characteristics and clinical values of $\mathrm{m} 6 \mathrm{~A}$ regulators in predicting prognosis in pancreatic cancer.

Methods: In our study, we obtained gene expression profiles with copy number variation (CNV) data and clinical characteristic data of 186 patients with pancreatic cancer from The Cancer Genome Atlas portal (TCGA). Then, we determined the alteration of m6a regulators and their correlation with clinicopathological features using the log-rank tests, Cox regression model, and chi-square test.

Results: The results suggested that pancreatic cancer patients with ALKBH5 CNV were associated with worse overall survival and diseasefree survival than those with diploid genes. Additionally, upregulation of the writer gene $A L K B H 5$ had a positive correlation with the activation of AKT pathways.

Conclusion: Our study not only demonstrated genetic characteristic changes of m6A-related genes in pancreatic cancer and found a strong relationship between the changes of ALKBH5 and poor prognosis but also provided a novel therapeutic target for pancreatic cancer therapy.

\section{Background}

Pancreatic cancer, especially pancreatic ductal adenocarcinoma (PDAC), is one of the most malignant tumors of the digestive system, causing approximately 350,000 deaths worldwide every year [1]. By the year of 2030, PDAC would be the second leading cause of cancerrelated mortality, surpassing lung cancer and colorectal cancer [2]. Although extensive studies on pancreatic cancer have been conducted over the past few decades, there is no substantial improvement in the prognosis of pancreatic cancer. The most optimal choice and therapeutic strategy for pancreatic cancer are still surgical resection combined with chemotherapy, but the unresectability rate is still high and the 5-year overall survival (OS) rate remains $<7 \%$, accompanied with a continuous elevation of its incidence [1]. To date, there are still no reliable gene signatures for treatment effects and prognosis and for early detection and improved therapies. Therefore, there is an urgent need to develop a method to predict whether a patient will have a relatively long survival time and better prognosis, based on the characteristics of transcriptome sequencing and genome sequencing. Screening and uncovering potential biomarkers of tumor heterogeneity have become a focus in cancer research [3], and most of the candidate genes for therapeutic target are closely related to pathogenic gene variants or to their tumor tissue-specific antigens [4-6]. Many problems related to pancreatic cancer treatment remain to be solved, especially in the field of exploring the underlying molecular mechanisms of the tumorigenesis of pancreatic cancer and new therapeutic targets.

In the last few decades, chemical modifications of nucleobases have become a focus in controlling gene expression in cancers at different levels because of their subsequent regulation in protein translation and modulation of signaling pathways, especially N6methyladenosine $(\mathrm{m} 6 \mathrm{~A})$ modification. $\mathrm{m} 6 \mathrm{~A}$ has been considered the major type of normal endogenous modification on RNA molecules including mRNAs [6], miRNAs [7], and IncRNAs [8]. Additionally, m6A modification has been confirmed to be a reversible process dependent on multiple m6A regulatory enzymes, which are classified as "writers (WTAP, METTL3, and METTL14)", "erasers (FTO and ALKBH5)" and "readers (YTHDF1, YTHDF2, YTHDF3, YTHDC1, and YTHDC2)"[9].

The effects of m6A are mainly determined by m6A readers, writers, and erasers. The writer complex includes methylase enzymes, while the erasers downregulate the m6A level. Furthermore, the readers regulate the balance between writers and erasers, sequentially producing a functional signal [10]. Dysregulation of m6A results in multiple physiological homeostasis dysfunction, and affects the tumorigenesis and progression of most human malignancies through various mechanisms [11].Therefore, m6A regulatory gene alternation also plays an vital role in multiple pathogenic mechanisms of human disease, especially in tumorigenesis [12]. However, the underlying mechanism of m6A regulatory genes is complex and involves multiple molecules and pathways [13]. Dysregulation of m6A regulatory genes in various cancers results in cancer cell EMT [14], apoptosis [15], and stem cell self-renewal [16], which are important in cancer progression. However, the relationship between m6A regulatory genes and pancreatic cancer is still unclear. Therefore, in our study, we obtained the RNAsequencing (RNA-Seq) gene expression profiles and patients' clinical information of 186 patients with pancreatic adenocarcinoma (PAAD) from The Cancer Genome Atlas (TCGA). Among them, we evaluated the change profiles of $10 \mathrm{~m} 6 \mathrm{~A}$ regulatory genes in pancreatic cancer and the relationship between these changes and clinicopathologic features, including survival. Finally, an alteration of ALKBH5 was identified, which could be considered as a biomarker for prognosis or a therapeutic target for pancreatic cancer therapy. 


\section{Methods \\ Data processing}

From the TCGA database, we analyzed the copy number variation (CNV) data and pathology reports of a total of 186 patients with pancreatic cancer. The up-and-down regulation CNV was assessed using segmentation analysis and the GISTIC algorithm. Next, to explore the relationship between the clinicopathological significance of PAAD patients and m6A regulatory genes, the cohort of 186 pancreatic cancer patients was divided into two groups: "with mutation and/or CNVs of these m6A regulatory genes" and "without CNVs and mutation". The mRNA expression data profiles of patients with pancreatic cancer were also acquired from the TCGA database, and then the mRNA expression levels were processed with log scale, exploring the association with CNVs.

\section{Gene set enrichment analysis (GSEA)}

GSEA software (GSEA 3.0) was downloaded from the website (https://www.gsea-msigdb.org/gsea/index.jsp)[16]. Herein, according to the expression level of $A L K B H 5$, GESA divided the PAAD samples into two groups( $A L K B H 5$ high group, ALKBH5 low group). Afterwards, hallmark gene set "h.all.v6.0.symbols.gmt" was setup in the GSEA to analyze 19726 genes involved in PAAD, and those with normalized $p$ value $<0.05$ were considered to be significantly enriched.

\section{Statistical analysis}

SPSS 22.0 (IBM, Chicago, USA) and GraphPad Prism 7.0 (GraphPad Software, La Jolla, CA, USA) were applied to analyze the data. Our study adopted the $\chi^{2}$ test or Mann-Whitney $U$ test to determine the relationship between $m 6 \mathrm{~A}$ regulatory genes with different alternations and clinical characteristics of PAAD patients. Kaplan-Meier curve and the log-rank test were adopted for analyzing the OS or/and diseasefree survival (DFS) with m6A gene regulators. Then, Cox proportional hazard regression model was used to analyze the relationship between m6A regulatory genes and clinicopathological characteristics of PAAD patients in terms of OS and DFS. A $p$-value $<0.05$ was considered to indicate a statistically significant difference.

\section{Results}

\section{Mutations and CNVs of m6A regulatory genes in patients with PAAD}

Within the TCGA database, only 19 independent samples were found to have mutations of m6A regulatory genes (Table 1) among the 186 cases based on the sequencing data; however, CNVs in ten m6A-related genes were observed in 177 PAAD samples based on the CNV data (Fig. 1A). The results showed that the m6A "writer" gene WTAP had the highest frequency of CNV events $(50.8 \%, 90 / 177)$ followed by $\operatorname{ALKBH5}(48.02 \%, 85 / 177)$, which is an m6A "eraser" gene. Furthermore, we also investigated the frequency of CNVs in KRAS (32.2\%), TP53 (54.2\%), SMAD4 (71.8\%), and CDKN2A (62.7\%) in this cohort.

Table 1

Mutations of m6A regulatory genes in 186 PDAC patients

\begin{tabular}{|c|c|c|c|c|c|c|c|}
\hline PAAD sample ID & ALKBH5 & FTO & METTL14 & METTL3 & WTAP & YTHDF1 YTHDF2 & YTHDC1 \\
\hline TCGA-IB-7651 & $\mathrm{R} 327 \mathrm{H}$ & R473W & & & & & \\
\hline TCGA-F2-A44G & & & R298H,X23_splice & & & & \\
\hline TCGA-2J-AABV & & & & $\mathrm{R} 471 \mathrm{H}$ & & & \\
\hline TCGA-IB-7651 & & & & A191V & & & \\
\hline TCGA-IB-7644 & & & & & C161Y & & \\
\hline TCGA-HZ-A9TJ & & & & & X49_splice & & \\
\hline TCGA-IB-AAUS & & & & & K155E & & \\
\hline TCGA-IB-A5SQ & & & & & & R404C & \\
\hline TCGA-IB-7651 & & & & & & & K565N,X374_splice, \\
\hline & & & & & & & E224K,Q168H \\
\hline
\end{tabular}


Next, we determined the CNVs of the above ten m6A regulatory genes in the PAAD samples, and found that the loss of copy number was the most frequent CNV event (350/548) (Fig. 1B and Table 2), which was the same as the CNV status in clear cell renal cell carcinoma (ccRCC) [17]. Among these CNVs, shallow deletion of WTAP ranked as the first in terms of the most frequent CNVs, and shallow deletion of both $A L K B H 5$ and YTHDF3 was the most frequent co-occurring CNV, indicating the important roles these two genes play in the process of m6A RNA modification.

Table 2

Different CNV patterns occur in PAAD samples $(n=177)$.

\begin{tabular}{|c|c|c|c|c|c|c|c|c|}
\hline & & Diploid & Deep deletion & Shallow deletion & Copy number gain & Amplification & CNV sum & Percentage \\
\hline \multirow[t]{2}{*}{ Eraser } & ALKBH5 & 92 & & 73 & 9 & 3 & 85 & $48.02 \%$ \\
\hline & FTO & 142 & & 12 & 22 & 1 & 35 & $19.8 \%$ \\
\hline \multirow[t]{3}{*}{ writers } & METTL14 & 140 & & 28 & 9 & & 37 & $20.9 \%$ \\
\hline & METTL3 & 128 & & 19 & 29 & 1 & 49 & $27.7 \%$ \\
\hline & WTAP & 87 & & 86 & 4 & & 90 & $50.8 \%$ \\
\hline \multirow[t]{9}{*}{ Reader } & YTHDF1 & 125 & & 7 & 44 & 1 & 52 & $29.4 \%$ \\
\hline & YTHDF2 & 113 & 1 & 58 & 5 & & 64 & $36.2 \%$ \\
\hline & YTHDF3 & 115 & & 17 & 40 & 5 & 62 & $35 \%$ \\
\hline & YTHDC1 & 141 & 1 & 26 & 9 & & 36 & $20.3 \%$ \\
\hline & YTHDC2 & 139 & & 22 & 16 & & 38 & $21.5 \%$ \\
\hline & KRAS & 120 & 1 & 14 & 36 & 6 & 57 & $32.2 \%$ \\
\hline & TP53 & 81 & 2 & 86 & 8 & & 96 & $54.2 \%$ \\
\hline & SMAD4 & 50 & 25 & 95 & 7 & & 127 & $71.8 \%$ \\
\hline & CDKN2A & 66 & 49 & 60 & 2 & & 111 & $62.7 \%$ \\
\hline
\end{tabular}

\section{Alterations of m6A regulatory genes are associated with clinicopathological and molecular characteristics}

We also assessed the association between variations (CNV and/or mutation) of the m6A-related regulators and the clinicopathological features of patients with PAAD. Similar to the ccRCC samples, the results of this study showed a close correlation between alterations of m6A regulatory genes and higher Fuhrman Nuclear Grade (Table 3) in PAAD samples. On account of the fact that KRAS, TP53, SMAD4, and $C D K N 2 A$ play important roles in the tumorigenesis of PAAD, we also assessed whether alterations of m6A regulatory genes were related to alterations of these four genes or not. As shown in Table 4, KRAS, TP53, SMAD4, and CDKN2A alterations in PAAD samples had a positive correlation with alterations of m6A regulatory genes as expected; meanwhile, one sample showed no alterations of m6A regulatory genes among the total 57 patients with KRAS CNV. 
Table 3

Clinical pathological parameters of PAAD patients with or without mutation/CNV of m6A regulatory genes.*

\begin{tabular}{|c|c|c|c|c|}
\hline & & With mutation and/or CNV* & Without mutation and $\mathrm{CNV}^{*}$ & $P$ \\
\hline \multirow[t]{2}{*}{ Age } & $<=60$ & 14 & 44 & \multirow[t]{2}{*}{0.695} \\
\hline & $>60$ & 32 & 87 & \\
\hline \multirow[t]{2}{*}{ Gender } & Male & 18 & 79 & \multirow[t]{2}{*}{0.013} \\
\hline & Female & 28 & 52 & \\
\hline \multirow[t]{6}{*}{ Pathological Stage } & ( & 2 & 5 & \multirow[t]{6}{*}{0.670} \\
\hline & ( & 9 & 15 & \\
\hline & प & 34 & 107 & \\
\hline & ( & 1 & 2 & \\
\hline & Discrepancy & 0 & 1 & \\
\hline & N/A & 0 & 1 & \\
\hline \multirow[t]{5}{*}{ Historical grade } & $\mathrm{G} 1$ & 13 & 17 & \multirow[t]{5}{*}{0.035} \\
\hline & $\mathrm{G} 2$ & 24 & 71 & \\
\hline & G3 & 7 & 41 & \\
\hline & $\mathrm{G} 4$ & 1 & 1 & \\
\hline & Gx & 1 & 1 & \\
\hline \multirow[t]{6}{*}{ T stage } & $\mathrm{T} 1$ & 9 & 12 & \multirow[t]{6}{*}{0.328} \\
\hline & $\mathrm{T} 2$ & 35 & 111 & \\
\hline & T3 & 1 & 2 & \\
\hline & $\mathrm{T} 4$ & 1 & 3 & \\
\hline & Tx & 0 & 3 & \\
\hline & NA & 0 & 3 & \\
\hline \multirow[t]{3}{*}{ M stage } & MO & 23 & 57 & \multirow[t]{3}{*}{0.870} \\
\hline & M1 & 1 & 3 & \\
\hline & $M x$ & 22 & 71 & \\
\hline \multirow[t]{4}{*}{ N stage } & NO & 12 & 37 & \multirow[t]{4}{*}{0.673} \\
\hline & N1 & 34 & 89 & \\
\hline & $\mathrm{Nx}$ & 0 & 4 & \\
\hline & NA & 0 & 1 & \\
\hline
\end{tabular}


Table 4

Relationship between molecular characteristics and m6A regulatory genes alteration in PAAD patients.

\begin{tabular}{|c|c|c|c|c|c|}
\hline & & Without mutation or CNV* & With mutation and CNV* & $\chi^{2}$ & $\mathbf{P}$ \\
\hline \multirow[t]{2}{*}{ KRAS } & Wt & 45 & 75 & \multirow[t]{2}{*}{25.671} & \multirow[t]{2}{*}{0.000} \\
\hline & Alteration & 1 & 56 & & \\
\hline \multirow[t]{2}{*}{ SMAD4 } & Wt & 32 & 18 & \multirow[t]{2}{*}{52.346} & \multirow[t]{2}{*}{0.000} \\
\hline & Alteration & 14 & 113 & & \\
\hline \multirow[t]{2}{*}{ TP53 } & Wt & 42 & 39 & \multirow[t]{2}{*}{51.936} & \multirow[t]{2}{*}{0.000} \\
\hline & Alteration & 4 & 92 & & \\
\hline \multirow[t]{2}{*}{ CDKN2A } & Wt & 42 & 24 & \multirow[t]{2}{*}{77.551} & \multirow[t]{2}{*}{0.000} \\
\hline & Alteration & 4 & 107 & & \\
\hline
\end{tabular}

Furthermore, we also evaluated the association between the m6A regulatory genes and mRNA expression. The results revealed that the ubiquitous CNVs were associated with the mRNA expression levels of m6A-related genes in 177 PAAD samples. Among these genes, the copy number gains were positively associated with higher mRNA expression, whereas the shallow deletions or deep deletions were negatively associated with lower mRNA expression (Fig. 2).

\section{Identification of the prognostic value of m6A regulatory gene CNVs in patients with PAAD}

The CNVs effects of m6A regulatory genes on the OS and DFS of patients with PAAD were evaluated. As shown in Fig. 3A-B, there was no correlation between m6A regulatory gene CNVs and OS/DFS among patients with PAAD. Furthermore, separate analysis of the ten m6A regulatory genes revealed a significant difference between patients with PAAD and those with alterations of $A L K B H 5$ (one eraser gene of m6A). Copy number gain or amplification with $A L K B H 5$ showed better OS and DFS (Fig. 3C-D); However, according to survival analysis of the CNVs of the other nine m6A-regulated genes, no significant differences were observed between the different separated subgroups (Figure S1). Additionally, ALKBH5 was determined as an independent risk factor for OS and DFS, as shown in Table 5. Combined with the results presented above, we suggested that PAAD patients with up-regulated ALKBH5 mRNA expression have a better survival. 
Table 5

Univariate and Multivariate COX regression analysis of m6A regulatory genes for PAAD patients' overall survival (OS) and disease-free survival (DFS)*.

\begin{tabular}{|c|c|c|c|c|c|c|c|c|}
\hline \multirow{3}{*}{ Variable } & \multicolumn{4}{|l|}{ os } & \multicolumn{4}{|l|}{ DFS } \\
\hline & Univariate & & Multivariate & & Univariate & Multivariate & Univariate & Multivariate \\
\hline & HR (95\% Cl) & $\mathrm{P}$ & $\mathrm{HR}$ & $\mathrm{P}$ & $\mathrm{HR}(95 \% \mathrm{Cl})$ & $\mathrm{P}$ & $\mathrm{HR}$ & $\mathrm{P}$ \\
\hline $\begin{array}{l}\text { Age }(>60 \text { vs }< \\
=60)\end{array}$ & $\begin{array}{l}1.383(0.883- \\
20165)\end{array}$ & 0.156 & $\begin{array}{l}1.387(0.854- \\
2.253)\end{array}$ & 0.187 & $\begin{array}{l}0.976(0.622- \\
1.533)\end{array}$ & 0.917 & $\begin{array}{l}0.733(0.446- \\
1.205)\end{array}$ & 0.221 \\
\hline $\begin{array}{l}\text { Gender (male } \\
\text { vs female) }\end{array}$ & $\begin{array}{l}1.192(0.793- \\
1.792)\end{array}$ & 0.398 & $\begin{array}{l}1.561(0.962- \\
2.533)\end{array}$ & 0.071 & $\begin{array}{l}1.137(0.732- \\
1.767)\end{array}$ & 0.568 & $\begin{array}{l}1.506(0.887- \\
2.556)\end{array}$ & 0.129 \\
\hline $\begin{array}{l}\text { Stage (I-II vs III- } \\
\text { IV) }\end{array}$ & $\begin{array}{l}1.165(0.835- \\
1.624)\end{array}$ & 0.369 & $\begin{array}{l}1.168(0.574- \\
2.376)\end{array}$ & 0.669 & $\begin{array}{l}2.120(1.111- \\
4.047)\end{array}$ & 0.023 & $\begin{array}{l}1.162(0.576- \\
2.346)\end{array}$ & 0.675 \\
\hline M (M1 vs M0) & $\begin{array}{l}1.050(0.251- \\
4.388)\end{array}$ & 0.947 & & & $\begin{array}{l}0.936(0.226- \\
3.885)\end{array}$ & 0.928 & & \\
\hline N (N1 vs N0) & $\begin{array}{l}2.151(1.281- \\
3.612)\end{array}$ & $0.004^{\star}$ & $\begin{array}{l}2.119(1.184- \\
3.793)\end{array}$ & $0.011^{*}$ & $\begin{array}{l}1.750(1.065- \\
2.875)\end{array}$ & 0.027 & $\begin{array}{l}1.488(0.844- \\
2.623)\end{array}$ & 0.169 \\
\hline $\begin{array}{l}\text { T (T3-T4 vs } \\
\text { T1-T2) }\end{array}$ & $\begin{array}{l}0.92(0.250- \\
2.513)\end{array}$ & 0.693 & $\begin{array}{l}0.878(0.258- \\
2.987)\end{array}$ & 0.835 & $\begin{array}{l}1.078(0.339- \\
3.431)\end{array}$ & 0.898 & $\begin{array}{l}1.455(0.419- \\
5.056)\end{array}$ & 0.555 \\
\hline $\begin{array}{l}\text { Grade }(3-5 \text { vs } \\
1-2)\end{array}$ & $\begin{array}{l}1.496(0.970- \\
2.308)\end{array}$ & 0.069 & $\begin{array}{l}1.146(0.709- \\
1.854)\end{array}$ & 0.578 & $\begin{array}{l}1.740(1.094- \\
2.767)\end{array}$ & 0.019 & $\begin{array}{l}1.424(0.854- \\
2.375)\end{array}$ & 0.175 \\
\hline $\begin{array}{l}\text { KRAS(altered } \\
\text { vs diploid) }\end{array}$ & $\begin{array}{l}1.170(0.75- \\
1.825)\end{array}$ & 0.490 & $\begin{array}{l}1.836(1.058- \\
3.185)\end{array}$ & 0.031 & $\begin{array}{l}0.890(0.547- \\
1.449)\end{array}$ & 0.640 & $\begin{array}{l}1.673(0.869- \\
3.219)\end{array}$ & 0.123 \\
\hline $\begin{array}{l}\text { TP53 (altered } \\
\text { vs diploid) }\end{array}$ & $\begin{array}{l}1.242(0.817- \\
1.889)\end{array}$ & 0.311 & $\begin{array}{l}1.140(0.672- \\
1.932)\end{array}$ & 0.628 & $\begin{array}{l}0.986(0.634- \\
1.533)\end{array}$ & 0.950 & $\begin{array}{l}0.986(0.561- \\
1.732)\end{array}$ & 0.961 \\
\hline $\begin{array}{l}\text { SMAD4 } \\
\text { (altered vs } \\
\text { diploid) }\end{array}$ & $\begin{array}{l}1.234(0.766- \\
1.987)\end{array}$ & 0.387 & $\begin{array}{l}1.066(0.590- \\
1.926)\end{array}$ & 0.831 & $\begin{array}{l}1.653(0.976- \\
2.800)\end{array}$ & 0.062 & $\begin{array}{l}1.095(0.568- \\
2.110)\end{array}$ & 0.786 \\
\hline $\begin{array}{l}\text { CDKN2A } \\
\text { (altered vs } \\
\text { diploid) }\end{array}$ & $\begin{array}{l}1.307(0.837- \\
2.042)\end{array}$ & 0.238 & $\begin{array}{l}0.950(0.667- \\
1.352)\end{array}$ & 0.774 & $\begin{array}{l}1.480(0.929- \\
2.356)\end{array}$ & 0.099 & $\begin{array}{l}0.915(0.619- \\
1.353)\end{array}$ & 0.657 \\
\hline $\begin{array}{l}\text { WTAP(write } \\
\text { lose vs others) }\end{array}$ & $\begin{array}{l}1.325(0.879- \\
1.998)\end{array}$ & 0.179 & $\begin{array}{l}1.291(0.799- \\
2.085)\end{array}$ & 0.298 & $\begin{array}{l}1.245(0.802- \\
1.932)\end{array}$ & 0.329 & $\begin{array}{l}1.255(0.729- \\
2.162)\end{array}$ & 0.412 \\
\hline $\begin{array}{l}\text { Mett|3(write } \\
\text { lose vs others) }\end{array}$ & $\begin{array}{l}0.918(0.488- \\
1.725)\end{array}$ & 0.790 & $\begin{array}{l}0.648(0.308- \\
1.364)\end{array}$ & 0.253 & $\begin{array}{l}1.269(0.670- \\
2.403)\end{array}$ & 0.464 & $\begin{array}{l}0.869(0.405- \\
1.867)\end{array}$ & 0.720 \\
\hline $\begin{array}{l}\text { Mett|14(write } \\
\text { lose vs others) }\end{array}$ & $\begin{array}{l}1.199(0.707- \\
2.034)\end{array}$ & 0.501 & $\begin{array}{l}1.378(0.747- \\
2.543)\end{array}$ & 0.305 & $\begin{array}{l}1.639(0.956- \\
2.812)\end{array}$ & 0.073 & $\begin{array}{l}1.970(1.037- \\
3.741)\end{array}$ & $0.038^{*}$ \\
\hline $\begin{array}{l}\text { FTO(eraser } \\
\text { gain vs others) }\end{array}$ & $\begin{array}{l}1.236(0.684- \\
2.234)\end{array}$ & 0.483 & $\begin{array}{l}0.968(0.483- \\
1.942)\end{array}$ & 0.928 & $\begin{array}{l}1.490(0.799- \\
2.778)\end{array}$ & 0.209 & $\begin{array}{l}1.062(0.499- \\
2.263)\end{array}$ & 0.875 \\
\hline $\begin{array}{l}\text { ALKBH5(eraser } \\
\text { gain vs others) }\end{array}$ & $\begin{array}{l}0.229(0.072- \\
0.731)\end{array}$ & $0.013^{*}$ & $\begin{array}{l}0.287(0.083- \\
0.988)\end{array}$ & $0.048^{*}$ & $\begin{array}{l}0.199(0.062- \\
0.641)\end{array}$ & 0.007 & $\begin{array}{l}0.201(0.053- \\
0.763)\end{array}$ & $0.018^{*}$ \\
\hline
\end{tabular}

\section{Enrichment analysis of ALKBH5 gain of function}

To confirm the above-mentioned conclusion of the relationship between up-regulated $A L K B H 5$ expression and better and prolong survival, we next evaluated $A L K B H 5$ mRNA expression among patients with PAAD whose prognosis were affected by $A L K B H 5$ mRNA level in Gene Expression Profiling and Interactive Analyses (GEPIA, http://gepia.cancer-pku.cn/index.html) [18]. As expected, patients with low $A L K B H 5$ mRNA expression had worse OS than those with high $A L K B H 5$ expression (Fig. 4A). However, ALKBH5 mRNA expression level had no statistically significant association with DFS in patients with PAAD (Fig. 4B). Considering $A L K B H 5$ as an "eraser" in the demethylation process, combining with the results of our study, we attempted to explore the dysregulation of $A L K B H 5$ in the pathogenesis of patients with PAAD. We examined the enriched gene sets in TCGA data sample with different $A L K B H 5$ mRNA expression levels with GSEA. GSEA analysis showed that the differential expression of ALKBH5 was related to some key biological processes involving PGC1A, AKT, and 
LONGEVITY signaling pathways (Table 6 and Fig. 4C-D), thus providing an indication of the underlying mechanism in the tumorigenesis of PAAD. Additionally, several studies have found that $A L K B H 5$ can participate in AKT signaling pathways, consistent with our assumption [19]. Further study is still needed to illustrate the potential effects of $A L K B H 5$ on the regulation of the downstream genes in pancreatic cancer.

Table 6

Gene sets enrichment of low ALKBH5 mRNA expression level in the PAAD cohort.

\begin{tabular}{|llllll|}
\hline GS DETAILS & SIZE & ES & NES & NOM $p$-val & FDR q-val \\
\hline BIOCARTA_PGC1A_PATHWAY & 23 & 0.53 & 1.60 & 0.029 & 1.000 \\
\hline BIOCARTA_AKT_PATHWAY & 22 & 0.54 & 1.53 & 0.046 & 1.000 \\
\hline BIOCARTA_LONGEVITY_PATHWAY & 15 & 0.66 & 1.47 & 0.028 & 1.000 \\
\hline
\end{tabular}

\section{Discussion}

Pancreatic cancer is one of the most common malignancies of the digestive system, and progress in research related to its treatment has been slow. In recent decades, the discovery of m6A has increased our understanding of tumorigenesis regulation to a new level, helping us gain insight into the role of methylation and demethylation in tumor formation and progression [20]. Many studies have demonstrated that m6A alternation is one of the key factors in cancer management [21]. However, the role of m6A regulatory genes in pancreatic cancer remains unclear. Upon analysis of the different expressions or mutations of "readers", "writers", and "erasers" in different tissues, we found that the genes related to m6A regulation seem to be different in distant tumors. Therefore, in this study, we aimed to screen and uncover m6A regulatory factors closely related to clinicopathological significance and prognosis in pancreatic cancer. This study not only determined the value of $\mathrm{m} 6 \mathrm{~A}$ regulatory genes for pancreatic cancer prognosis but also proposed a novel therapeutic target for pancreatic cancer.

As a demethylase, ALKBH5 is involved in the mediation of methylation reversal. It has been reported that ALKBH5 is overexpressed in various cancers, including breast cancer [22], glioblastoma [23], ovarian cancer [24], and gastric cancer [25, 26]. Additionally, signaling associated with multiple cancers is dysregulated in PAAD development. We found that in patients with PAAD, a high ALKBH5 mRNA expression level was associated with the activation of AKT signaling pathways, which participate in important cellular pathological processes in PAAD development [27], suggesting that the mRNAs of molecules in the AKT pathway may be the m6a modification target mediated by ALKBH5 [28]. Recently, a study has shown that ALKBH5 functions as an anti-tumor protein in pancreatic cancer progression [29]; in this paper, upregulated ALKBH5 sensitized pancreatic cancer to gemcitabine-chemotherapy, and knockdown of ALKBH5 decreased pancreatic cancer cell invasion, migration, proliferation, metastasis, and tumorigenesis. [29]. As in the case of colorectal cancer [30], $A L K B H 5$ showed obviously weaker mRNA expression in pancreatic cancer than in the normal tissue. However, in contrast to the case of rectal adenocarcinoma wherein high $A L K B H 5$ expression in tumor tissues was clearly associated with worse OS, $A L K B H 5$ expression in pancreatic cancer was found to be positively associated with OS in TCGA.

We also evaluated the effect of m6A regulatory gene alterations on the survival of patients with PAAD. In line with the characteristics of genetic alterations of m6A-related genes, the eraser gene $A L K B H 5$ was the only gene among the ten regulators that was associated with the OS and DFS. This confirmed that "erasers" are the main regulators of m6A in PAAD. A better OS was observed in patients with eraser gene gain of function, making it clear that a decreased level of m6A plays a significant role in PAAD progression. However, we failed to obtain any significant results with regard to the relationship between the other nine m6A regulatory gene alterations and OS or DFS, possibly because of the limited number of patients. Direct detection of the m6A level and evaluation of its effect on PAAD survival in a new and larger cohort are needed to illustrate this contradictory phenomenon.

We also assessed the impact of m6A-related gene changes on prognosis, especially OS and DFS, in patients with PAAD. According to the genetic changes of m6A-related gene characteristics, only ALKBH5, an eraser gene, was associated with OS and DFS among the 10 regulatory genes. This confirms that erasers might be the predominant governors of $\mathrm{m} 6 \mathrm{~A}$ in PAAD. The patients with gained function of $A L K B H 5$ achieved better OS, indicating that decreased m6A levels may play an important role in the progression of PAAD. However, we were unable to derive any significant results on the relationship between the other nine m6A regulatory gene changes and OS or DFS, possibly due to the limited number of patients. To account for this paradox, m6A levels need to be directly detected and their impact on PAAD survival should be evaluated in a new and larger cohort. 
In conclusion, we screened alternations of ten m6A regulatory genes in the TCGA database of pancreatic cancer patients, and identified that $A L K B H 5$ was the most valuable prognosis-related gene that may be associated with AKT signaling pathways. These findings revealed a novel molecular mechanism of PDAC tumorigenesis regulated by $\mathrm{m} 6 \mathrm{~A}$ modification and provided a new insight into the development of effective therapeutic strategies for the treatment of pancreatic cancer. Although we provided robust evidence for the prognostic value of the effect of ALKBH5 on pancreatic cancer, the underlying mechanism is not yet fully characterized. Thus, the effects of ALKBH5 clearly deserve further investigation.

\section{Declarations}

\section{Ethics declarations}

All the clinical and sequencing data were downloaded from the public database TCGA according to relevant user guidelines. Therefore, it can be ascertained that all patients provided written informed consent.

\section{Availability of data and materials}

Publicly available datasets were analyzed in this study, these can be found in The Cancer Genome Atlas (https://portal.gdc.cancer.gov/) by cBioportal platform[31] and TCGA-assembler[32], which are open to the public under some guidelines. Therefore, it is confirmed that all written informed consent was obtained. The data analyzed during the current study are available from the corresponding author on reasonable request.

\section{Author information}

Bi Lin and Hongwei Sun contributed equally to this work.

\section{Affiliations}

The First Affiliated Hospital of Wenzhou Medical University, Nan Baixiang Town , Wenzhou, Zhejiang 325000, P.R. China

Bi Lin, Hongwei Sun, Dinglai Yu, Yukai Xiang, Jie Zhang, Shengchuan Chen, Shengjie Dai, Chaohao Huang

\section{Author contribution}

The study conception and design were performed by Chaohao Huang. Material preparation, data collection, and analysis were performed by Dinglai Yu, Yukai Xiang, Jie Zhang, Shengchuan Chen, and Shengjie Dai. The first draft of the manuscript was written by Chaohao Huang $\triangle B i$ Lin and Hongwei Sun. All authors commented on previous versions of the manuscript. All authors read and approved the final manuscript.

\section{Corresponding author}

Correspondence to Chaohao Huang

\section{Acknowledgments}

We would like to thank Editage (www.editage.cn) for the English language editing.

\section{Funding}

The work was supported by the funds from the PhD Start-up Funding of the First Affiliated Hospital of Wenzhou Medical University, Zhejiang, China [No. 2019QD004].

\section{Competing interests}

The authors have no conflicts of interest to declare.

\section{Consent for publication}

Not applicable 


\section{References}

1. Lucas AL, Malvezzi M, Carioli G, Negri E, La Vecchia C, Boffetta P, Bosetti C. Global Trends in Pancreatic Cancer Mortality From 1980 Through 2013 and Predictions for 2017. Clin Gastroenterol Hepatol. 2016;14:1452-62 e1454.

2. Rahib L, Smith BD, Aizenberg R, Rosenzweig AB, Fleshman JM, Matrisian LM. Projecting cancer incidence and deaths to 2030: the unexpected burden of thyroid, liver, and pancreas cancers in the United States. Cancer Res. 2014;74:2913-21.

3. McGranahan N, Swanton C. Clonal Heterogeneity and Tumor Evolution: Past, Present, and the Future. Cell. 2017;168:613-28.

4. Bailey MH, Tokheim C, Porta-Pardo E, Sengupta S, Bertrand D, Weerasinghe A, Colaprico A, Wendl MC, Kim J, Reardon B, Kwok-Shing Ng P, Jeong KJ, Cao S, Wang Z, Gao J, Gao Q, Wang F, Liu EM, Mularoni L, Rubio-Perez C, Nagarajan N, Cortes-Ciriano I, Zhou DC, Liang WW, Hess JM, Yellapantula VD, Tamborero D, Gonzalez-Perez A, Suphavilai C, Ko JY, Khurana E, Park PJ, Van Allen EM, Liang H, Group MCW, N Cancer Genome Atlas Research, MS Lawrence, Godzik A, Lopez-Bigas N, Stuart J, Wheeler D, Getz G, Chen K, Lazar AJ, Mills GB, Karchin R, Ding L, Comprehensive Characterization of Cancer Driver Genes and Mutations, Cell, 174 (2018) $1034-1035$.

5. Aguirre AJ, Nowak JA, Camarda ND, Moffitt RA, Ghazani AA, Hazar-Rethinam M, Raghavan S, Kim J, Brais LK, Ragon D, Welch MW, Reilly E, McCabe D, Marini L, Anderka K, Helvie K, Oliver N, Babic A, Da Silva A, Nadres B, Van Seventer EE, Shahzade HA, St Pierre JP, Burke KP, Clancy T, Cleary JM, Doyle LA, Jajoo K, McCleary NJ, Meyerhardt JA, Murphy JE, Ng K, Patel AK, Perez K, Rosenthal MH, Rubinson DA, Ryou M, Shapiro GI, Sicinska E, Silverman SG, Nagy RJ, Lanman RB, Knoerzer D, Welsch DJ, Yurgelun MB, Fuchs CS, Garraway LA, Getz G, Hornick JL, Johnson BE, Kulke MH, Mayer RJ, Miller JW, Shyn PB, Tuveson DA, Wagle N, Yeh JJ, Hahn WC, R.B. Corcoran SL, Carter, B.M. Wolpin. Real-time Genomic Characterization of Advanced Pancreatic Cancer to Enable Precision Medicine, Cancer Discov, 8 (2018) 1096-1111.

6. Balachandran VP, Luksza M, Zhao JN, Makarov V, Moral JA, Remark R, Herbst B, Askan G, Bhanot U, Senbabaoglu Y, Wells DK, Cary CIO, Grbovic-Huezo O, Attiyeh M, Medina B, Zhang J, Loo J, Saglimbeni J, Abu-Akeel M, Zappasodi R, Riaz N, Smoragiewicz M, Kelley ZL, Basturk O, I Australian Pancreatic Cancer Genome, R. Garvan Institute of Medical, H. Prince of Wales, H. Royal North Shore, G. University of, H. St Vincent's, Q.B.M.R. Institute, C.f.C.R. University of Melbourne, I.f.M.B. University of Queensland, H Bankstown, Liverpool H, Royal Prince COBL, Hospital A, Westmead H, Fremantle H, H St John of God, H. Royal Adelaide, Flinders Medical C, Envoi P, Princess Alexandria H, Austin H, I. Johns Hopkins Medical, A.R.-N.C.f.A.R.o. Cancer M, Gonen AJ, Levine PJ, Allen DT, Fearon M, Merad S, Gnjatic CA, lacobuzio-Donahue JD, Wolchok RP, DeMatteo TA, Chan BD, Greenbaum T, Merghoub, S.D. Leach, Identification of unique neoantigen qualities in long-term survivors of pancreatic cancer, Nature, 551 (2017) 512-516.

7. Alarcon CR, Goodarzi H, Lee H, Liu X, Tavazoie S, Tavazoie SF, HNRNPA2B1 Is a Mediator of m(6)A-Dependent Nuclear RNA Processing Events, Cell, 162 (2015) 1299-1308.

8. Yang D, Qiao J, Wang G, Lan Y, Li G, Guo X, Xi J, Ye D, Zhu S, Chen W, Jia W, Leng Y, Wan X, Kang J. N6-Methyladenosine modification of lincRNA 1281 is critically required for mESC differentiation potential. Nucleic Acids Res. 2018;46:3906-20.

9. Meyer KD, Jaffrey SR. Rethinking m(6)A Readers, Writers, and Erasers. Annu Rev Cell Dev Biol. 2017;33:319-42.

10. Zheng W, Dong X, Zhao Y, Wang S, Jiang H, Zhang M, Zheng X, Gu M. Multiple Functions and Mechanisms Underlying the Role of METTL3 in Human Cancers. Front Oncol. 2019;9:1403.

11. Liu T, Wei Q, Jin J, Luo Q, Liu Y, Yang Y, Cheng C, Li L, Pi J, Si Y, Xiao H, Li L, Rao S, Wang F, Yu J, Yu J, Zou D, Yi P. The m6A reader YTHDF1 promotes ovarian cancer progression via augmenting EIF3C translation, Nucleic Acids Res, (2020).

12. Meng Y, Li S, Gu D, Xu K, Du M, Zhu L, Chu H, Zhang Z, Wu Y, Fu Z, Wang M, Genetic variants in m6A modification genes are associated with colorectal cancer risk, Carcinogenesis, (2019).

13. Zhang SY, Zhang SW, Fan XN, Meng J, Chen Y, Gao SJ, Huang Y. Global analysis of N6-methyladenosine functions and its disease association using deep learning and network-based methods. PLoS Comput Biol. 2019;15:e1006663.

14. Yue B, Song C, Yang L, Cui R, Cheng X, Zhang Z, Zhao G. METTL3-mediated N6-methyladenosine modification is critical for epithelialmesenchymal transition and metastasis of gastric cancer. Mol Cancer. 2019;18:142.

15. Paris J, Morgan M, Campos J, Spencer GJ, Shmakova A, Ivanova I, Mapperley C, Lawson H, Wotherspoon DA, Sepulveda C, Vukovic M, Allen L, Sarapuu A, Tavosanis A, Guitart AV, Villacreces A, Much C, Choe J, Azar A, van de Lagemaat LN, Vernimmen D, Nehme A, Mazurier F, Somervaille TCP, Gregory RI, O'Carroll D, Kranc KR, Targeting the RNA m(6)A Reader YTHDF2 Selectively Compromises Cancer Stem Cells in Acute Myeloid Leukemia, Cell Stem Cell, 25 (2019) 137-148 e136.

16. Jia R, Chai P, Wang S, Sun B, Xu Y, Yang Y, Ge S, Jia R, Yang YG, Fan X. m(6)A modification suppresses ocular melanoma through modulating HINT2 mRNA translation. Mol Cancer. 2019;18:161.

17. Zhou J, Wang J, Hong B, Ma K, Xie H, Li L, Zhang K, Zhou B, Cai L, Gong K. Gene signatures and prognostic values of m6A regulators in clear cell renal cell carcinoma - a retrospective study using TCGA database. Aging. 2019;11:1633-47.

Page 10/15 
18. Tang Z, Li C, Kang B, Gao G, Li C, Zhang Z. GEPIA: a web server for cancer and normal gene expression profiling and interactive analyses. Nucleic Acids Res. 2017;45:W98-102.

19. Zhang C, Zhang M, Ge S, Huang W, Lin X, Gao J, Gong J, Shen L. Reduced m6A modification predicts malignant phenotypes and augmented Wnt/PI3K-Akt signaling in gastric cancer. Cancer Med. 2019;8:4766-81.

20. Wang S, Chai P, Jia R, Jia R. Novel insights on m(6)A RNA methylation in tumorigenesis: a double-edged sword. Mol Cancer. 2018;17:101.

21. Pinello N, Sun S, Wong JJ. Aberrant expression of enzymes regulating m(6)A mRNA methylation: implication in cancer. Cancer Biol Med. 2018;15:323-34.

22. Zhang C, Samanta D, Lu H, Bullen JW, Zhang H, Chen I, He X, Semenza GL. Hypoxia induces the breast cancer stem cell phenotype by HIF-dependent and ALKBH5-mediated m(6)A-demethylation of NANOG mRNA. Proc Natl Acad Sci U S A. 2016;113:E2047-56.

23. Zhang S, Zhao BS, Zhou A, Lin K, Zheng S, Lu Z, Chen Y, Sulman EP, Xie K, Bogler O, Majumder S, He C, Huang S. m(6)A Demethylase ALKBH5 Maintains Tumorigenicity of Glioblastoma Stem-like Cells by Sustaining FOXM1 Expression and Cell Proliferation Program. Cancer Cell. 2017;31:591-606 e596.

24. Zhu H, Gan X, Jiang X, Diao S, Wu H, Hu J. ALKBH5 inhibited autophagy of epithelial ovarian cancer through miR-7 and BCL-2. J Exp Clin Cancer Res. 2019;38:163.

25. Hu BB, Wang XY, Gu XY, Zou C, Gao ZJ, Zhang H, Fan Y. N(6)-methyladenosine (m(6)A) RNA modification in gastrointestinal tract cancers: roles, mechanisms, and applications. Mol Cancer. 2019;18:178.

26. Su Y, Huang J, Hu J. m(6)A RNA Methylation Regulators Contribute to Malignant Progression and Have Clinical Prognostic Impact in Gastric Cancer. Front Oncol. 2019;9:1038.

27. Meng Q, Shi S, Liang C, Liang D, Hua J, Zhang B, Xu J, Yu X, Abrogation of glutathione peroxidase-1 drives EMT and chemoresistance in pancreatic cancer by activating ROS-mediated Akt/GSK3beta/Snail signaling, Oncogene, 37 (2018) 5843-5857.

28. Wang HF, Kuang MJ, Han SJ, Wang AB, Qiu J, Wang F, Tan BY, Wang DC, BMP2 Modified by the m(6)A Demethylation Enzyme ALKBH5 in the Ossification of the Ligamentum Flavum Through the AKT Signaling Pathway, Calcif Tissue Int, (2020).

29. Tang B, Yang Y, Kang M, Wang Y, Wang Y, Bi Y, He S, Shimamoto F. m(6)A demethylase ALKBH5 inhibits pancreatic cancer tumorigenesis by decreasing WIF-1 RNA methylation and mediating Wnt signaling. Mol Cancer. 2020;19:3.

30. Liu X, Liu L, Dong Z, Li J, Yu Y, Chen X, Ren F, Cui G, Sun R. Expression patterns and prognostic value of m(6)A-related genes in colorectal cancer. Am J Transl Res. 2019;11:3972-91.

31. Gao J, Aksoy BA, Dogrusoz U, Dresdner G, Gross B, Sumer SO, Sun Y, Jacobsen A, Sinha R, Larsson E, Cerami E, Sander C, Schultz N. Integrative analysis of complex cancer genomics and clinical profiles using the cBioPortal. Sci Signal. 2013;6:pl1.

32. Zhu Y, Qiu P, Ji Y. TCGA-assembler: open-source software for retrieving and processing TCGA data. Nat Methods. 2014;11:599-600.

\section{Figures}


A

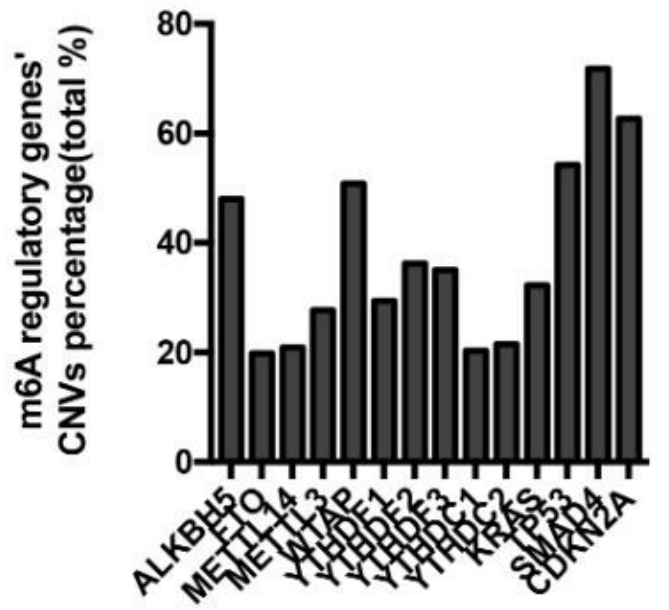

C

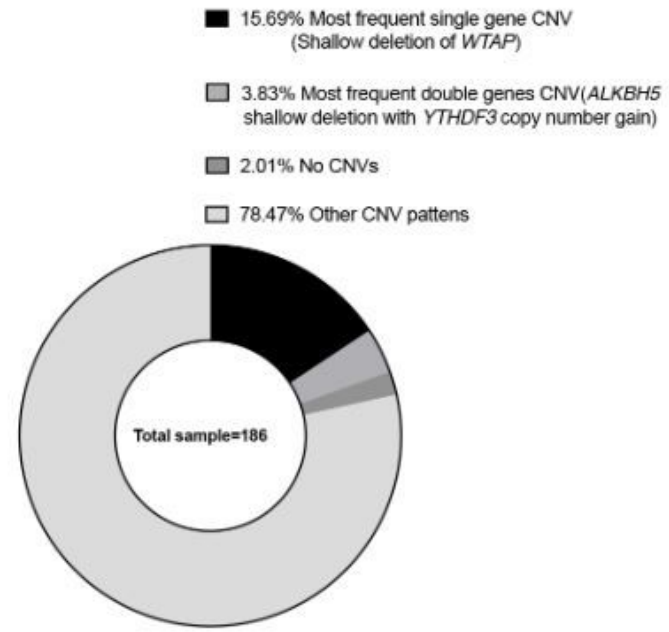

B

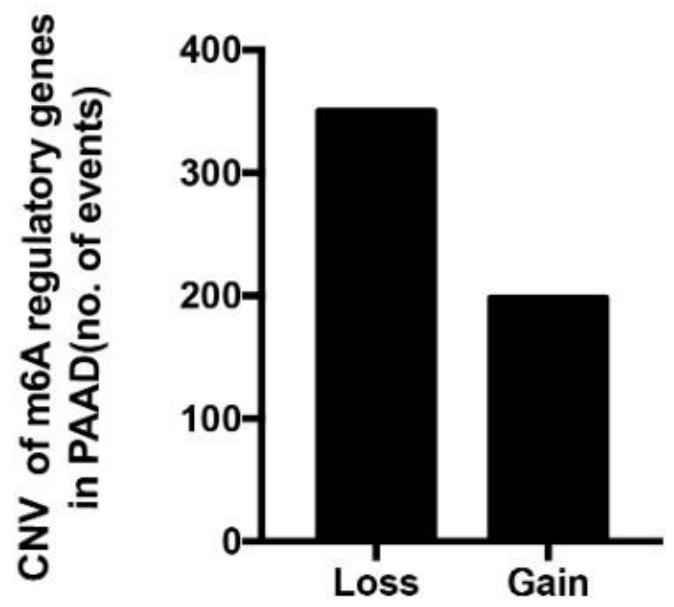

Figure 1

CNV characteristics of m6A regulatory genes in PAAD. (A) Percentage of PAAD samples with CNVs of m6A regulators, based on the data from TCGA. (B) Events of copy number gain or loss of m6A regulatory genes in PAAD samples. (C) The most common patterns of CNVs in m6A regulatory genes in the PAAD samples. 

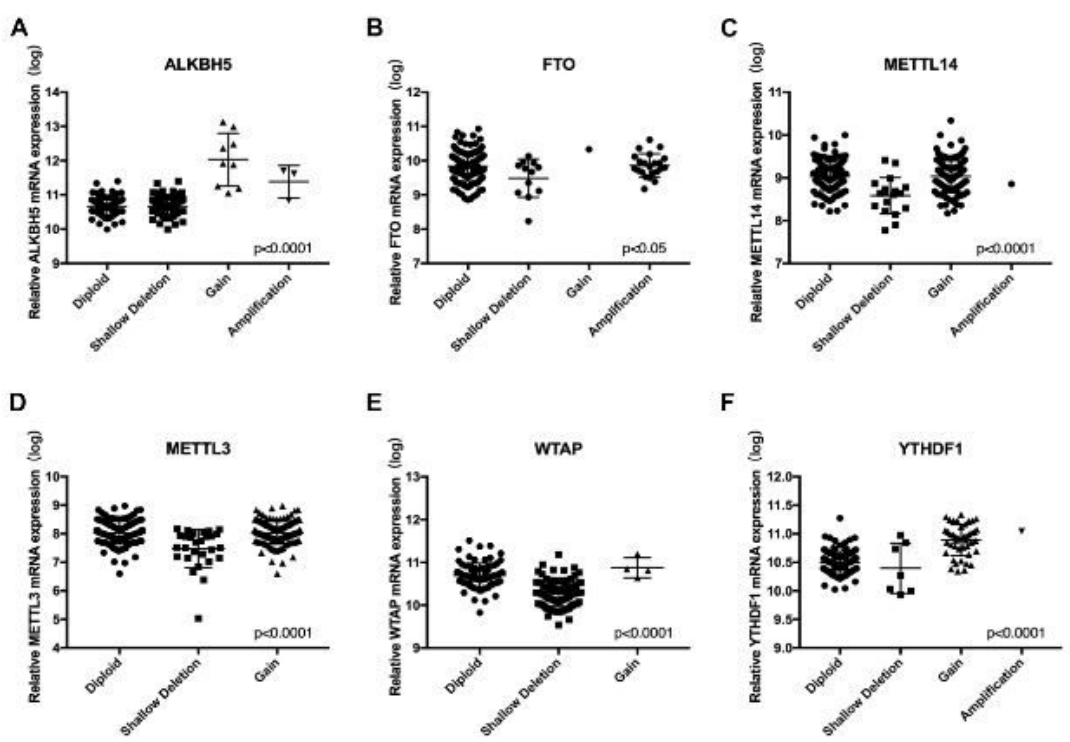

$\mathbf{F}$
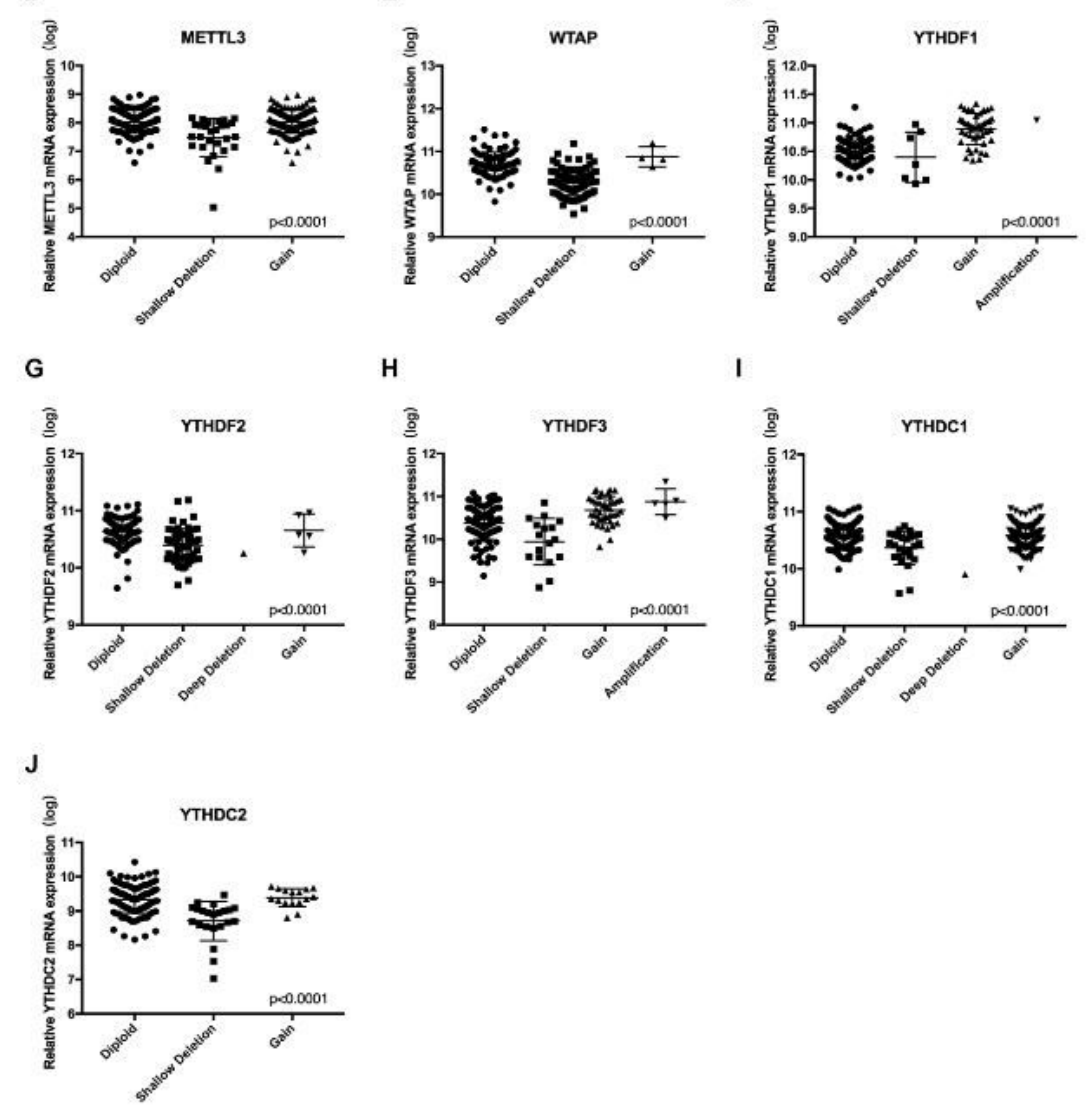

Figure 2

The relationship between different CNV patterns and mRNA expression levels of ten m6A regulatory genes in PAAD samples. 
A

\section{Overall Survival}

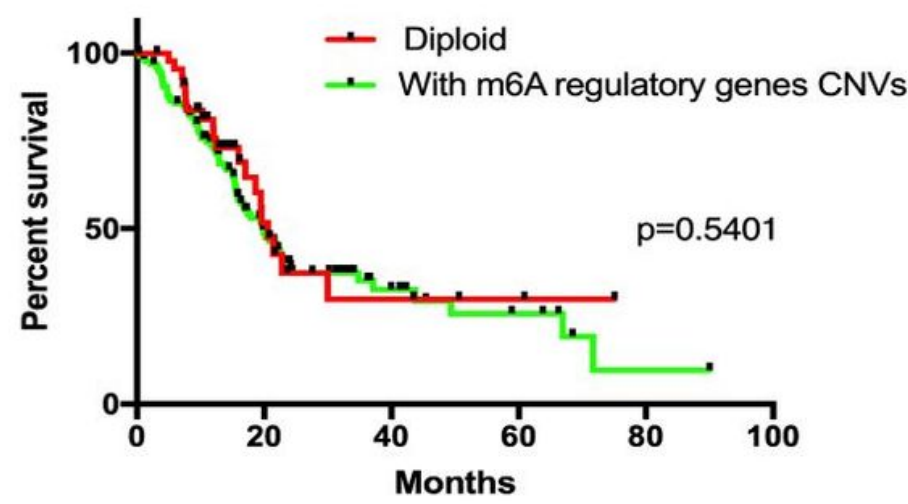

C

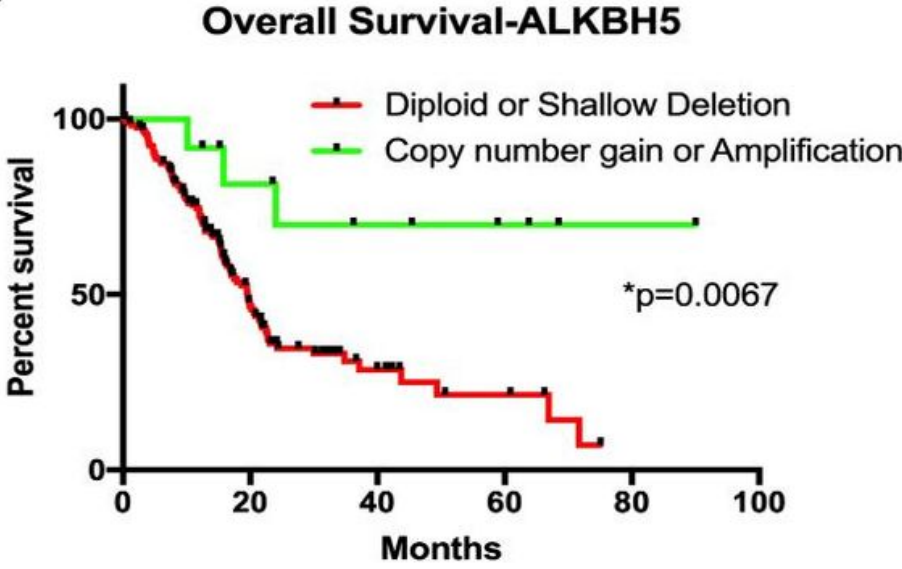

B

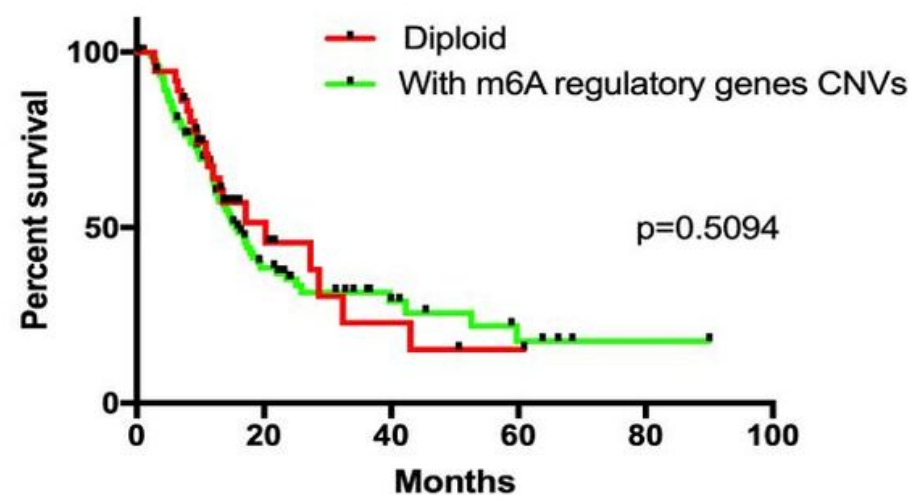

D

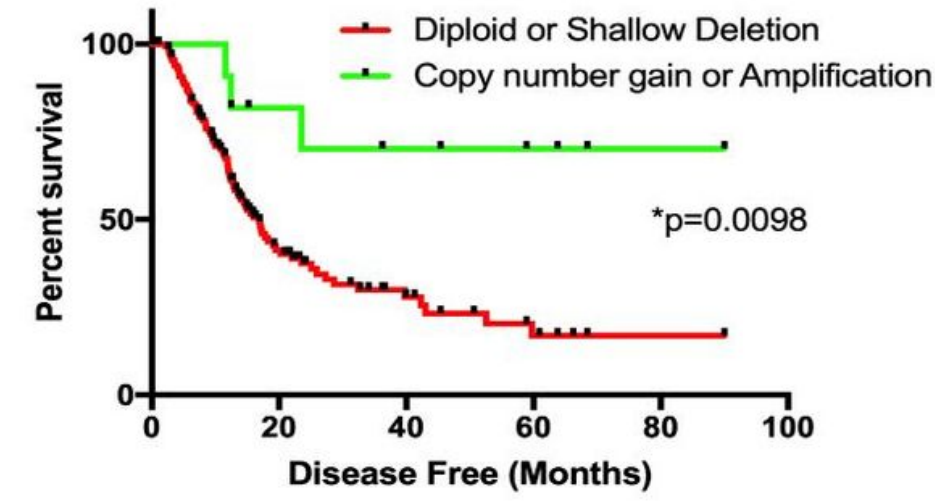

Figure 3

The overall survival of patients with PAAD with CNVs of m6A regulatory genes. (A-B) OS and DFS of patients with any of the CNVs of m6A regulatory genes or with diploid genes. (C-D) OS and DFS of patients with different CNV types of ALKBH5. 
A

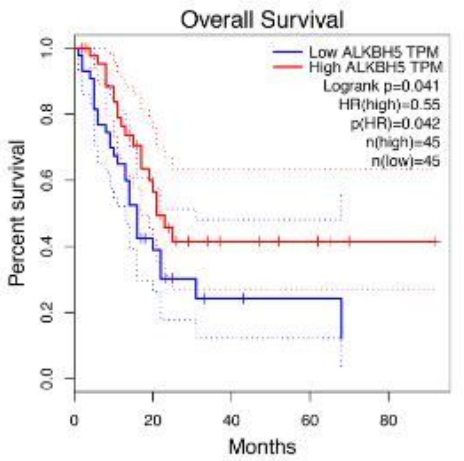

C

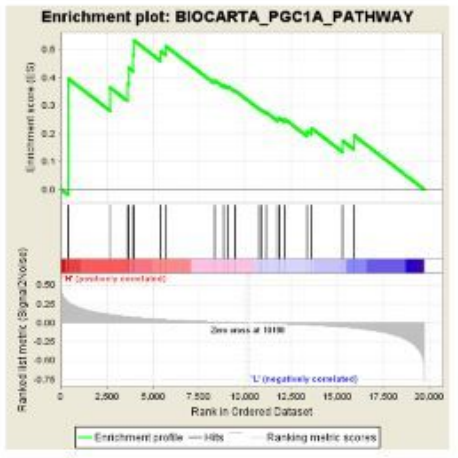

$\mathbf{E}$

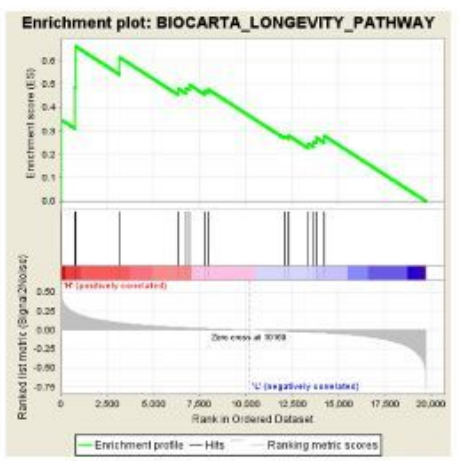

B

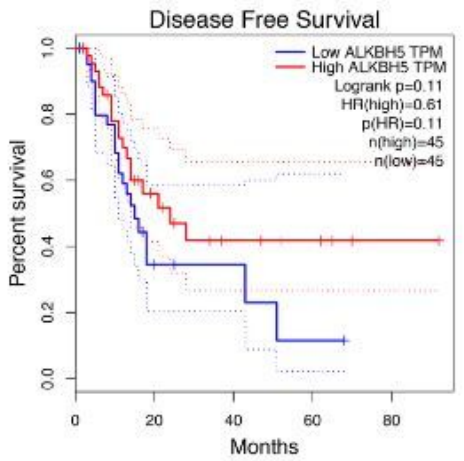

D

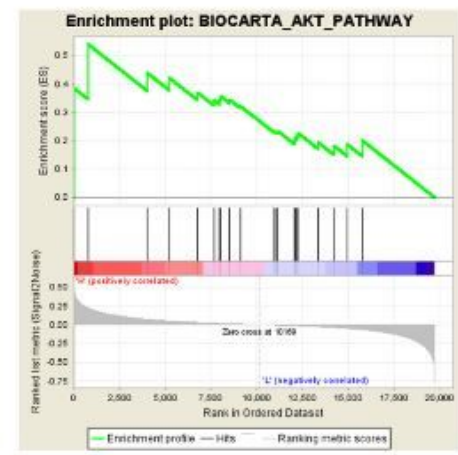

\section{Figure 4}

Functions of different expression levels of ALKBH5. (A-B) OS and DFS of patients with different ALKBH5 mRNA levels. Gene set enrichment plots of (C) PGC1A, (D) AKT signaling, and (E) LONGEVITY to ALKBH5 mRNA levels in the PAAD samples.

\section{Supplementary Files}

This is a list of supplementary files associated with this preprint. Click to download.

- figure1S.tif 